\title{
Arctic sea-ice oscillation: regional and seasonal perspectives
}

\author{
Jia WAng, ${ }^{1}$ Moto IkedA ${ }^{1,2}$ \\ ${ }^{1}$ International Arctic Research Center-Frontier Research System for Global Change, University of Alaska Fairbanks, \\ Fairbanks, AK 99775-7320, U.S.A. \\ ${ }^{2}$ Graduate School of Environmental Earth Science, Hokkaido University, Sapporo, Hokkaido 060, Japan
}

\begin{abstract}
Variability of the sea-ice cover (extent) in the Northern Hemisphere (Arctic and subpolar regions) associated with the Arctic Oscillation (AO) is investigated using historical data from 1901 to 1997. A principal-component analysis (empirical orthogonal functions (EOFs)) was applied to sea-ice area (SIA) anomalies for the period 1953-95. The leading EOF mode for the SIA anomaly shows an in-phase fluctuation in response to the AO and is called the Arctic sea-ice oscillation (ASIO). Arctic sea ice experiences seasonal variations that differ in timing and magnitude. Four types of seasonal variation are identified in the Arctic sea ice, and are superimposed on long-term interannual to decadal variability. Consistent with the total Arctic SIA anomaly, eight regional SIA anomalies have shown significant in-phase decrease (downward trend) since 1970, possibly part of a very long-term (century) cycle. Thus, it is recommended that SIA anomalies in the sensitive seasons be used to better capture interannual, interdecadal and longer (century) variability. Major decadal and interdecadal time-scales of SIA anomalies are found at 12-14 and 17-20 years. In the Sea of Okhotsk, a century time-scale is evident. The reduction rate (negative trend) of the total Arctic sea-ice cover in the last three decades is $-4.5 \%$ per decade, with the summer rate being the highest $(-10.2 \%$ per decade). The contribution to this total reduction varies from region to region, with sea-ice cover in the Greenland and Norwegian Seas experiencing the highest reduction rate of $-20.2 \%$ per decade.
\end{abstract}

\section{INTRODUGTION}

The Arctic Oscillation $(\mathrm{AO})$ is the dominant mode of atmospheric variability in the Northern Hemisphere (Kerr, 1999). This has become increasingly evident since 1990 (Baldwin and others, 1994; Kitoh and others, 1996; Kodera and others, 1996). Since 1989, a decrease in sea-level pressure (SLP) has been observed in the central Arctic (Walsh and others, 1996). Based on Kitoh and others (1996) and Thompson and Wallace (1998; TW98 hereafter), the AO, which is associated with the polar vortex aloft, might include the North Atlantic Oscillation (NAO) (Van Loon and Rogers, 1978; Hurrel and Van Loon, 1997) as a subset, depending on the domain being considered.

The Arctic climate system is hypothesized to be a feedback loop of the atmosphere-ice-ocean decadal oscillation (Mysak and others, 1990; Mysak and Venegas, 1998 (MV98 hereafter)), based on the singular value decomposition (SVD) complex empirical orthogonal function (EOF) analysis of SLP and sea-ice concentration (SIC) data from 1953-92. Arctic sea-ice variability is investigated in the context of recent atmospheric circulation trends (Slonosky and others, 1997; Deser and others, 2000). The winter sea-ice variability has a dipolar structure between the Baffin Bay-Davis Strait-Labrador Sea region and the Greenland-Norwegian seas (Wang and others, 1994; Mysak and others, 1996), while the summer sea-ice anomaly has a relatively uniform structure in space (Deser and others, 2000), indicating an in-phase variability (Wang and Ikeda, 2000; WI00 hereafter).

The Arctic sea-ice oscillation (ASIO) is defined as an inphase fluctuation of the Arctic sea-ice area (SIA) anomalies (WI00) in response to the AO, i.e. the AO-related surface air temperature (SAT) and SLP anomalies. The in-phase (or spatially uniform) decline of Arctic sea-ice cover in the last three decades is the major feature of the ASIO. The ASIO can be discretely described as hypersensitive decadal oscillations in the Arctic/subarctic climate (atmosphereice-ocean) system, triggered by the enhanced atmosphereocean interaction (or positive feedback) due to reduced ice thickness in the Arctic (Ikeda and others, 2001). The remarkable decadal oscillations of the Arctic sea-ice cover in the last 30 years are attributable to a persistent reduction of sea-ice thickness (and/or sea-ice cover) in the Arctic (Ikeda and others, 2001). Therefore, the Arctic sea-ice cover anomaly should not be regarded as a passive player in the Arctic climate system (Wu and others, 1999).

This study aims to identify the regional signatures of the ASIO by providing a regional perspective on the SIA anomalies, and will also investigate the following questions:

(1) What are the regional character and seasonality of seaice extent in different regions?

(2) Which seasons better reflect interannual variability and decadal oscillations in different regions?

(3) What are the decline rates in sea-ice cover in the last three decades in different seasons and different regions which may trigger the ASIO?

(4) What are the major cycles of SIA anomalies?

The data analyzed are briefly described in section 2 . Four types of seasonality, their variability (standard deviation) and the interannual variability of the Arctic sea-ice cover are investigated in section 3. We present the results of 


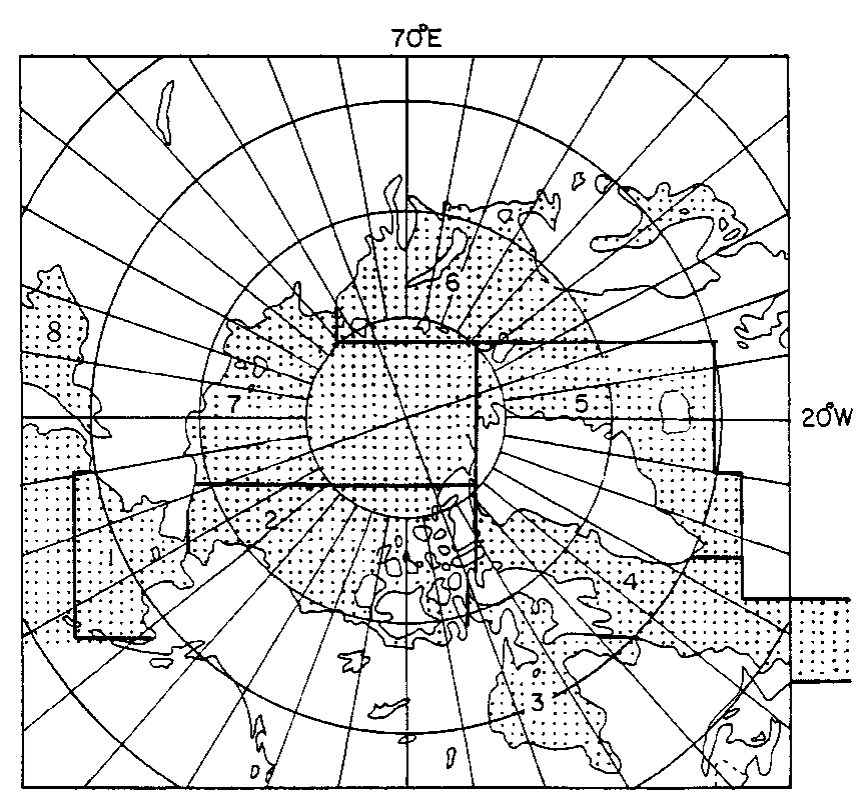

Fig. 1. The Arctic and subpolar region divided into the eight regions used in this study.

Table 1. Names of eight regions shown in Figure 1

\begin{tabular}{cl}
\hline Region & Name \\
\hline 1 & Bering Sea \\
2 & Beaufort and Chukchi Seas and Canadian Archipelago \\
3 & Hudson Bay \\
4 & Baffin Bay/Davis Strait and Labrador Sea \\
5 & Greenland and Norwegian Seas \\
6 & Barents and Kara Seas \\
7 & East Siberian and Laptev Seas and central Arctic \\
8 & Sea of Okhotsk \\
\hline
\end{tabular}

spatial and temporal patterns of the leading EOF modes of SIA anomalies and SAT using data from 1953-95 in section 4. Section 5 presents some statistics of 95 year data and trends of the last three decades in both seasonal and annual views. Section 6 summarizes our findings and refers to possible future research.

\section{THE DATA}

The monthly SIC data that were analyzed, as described by Walsh and Johnson (1979), are similar to those used in Wang and others $(1994,1995)$. The data sources and processing techniques are further summarized by Chapman and Walsh (1993). This study uses sea-ice data updated by the U.S. National Snow and Ice Data Center (NSIDC, 1998) using NASA-derived Scanning Multichannel Microwave Radiometer (SMMR)/Special Sensor Microwave/Imager (SSM/ I) sources from October 1978 (Cavalieri and others, 1997; Parkinson and others, 1999). This dataset has been updated to March 1995 and covers the Arctic Ocean and the adjacent seas with $a 1^{\circ}$ by $1^{\circ}$ latitude-latitude grid. The monthly SLP data were obtained directly from the U.S. National Center for Atmospheric Research (NCAR) for the period 1899-1997, archived on $5^{\circ}$ by $5^{\circ}$ global grids. The SAT data were from the period 1850-1997 (Jones, 1994). The SIC data from the periods 1953-95 and 1901-95 were used in this study. The
EOF analysis results show that both periods produce similar spatial and temporal patterns, although data before 1953 may contain some uncertainty. Thus, the EOF analysis results for the period 1953-95 are presented in this study in comparison to the EOF analysis using data for the period 1901-95 (WI00).

The Arctic SIC grids (Walsh and Johnson, 1979; Mysak and Manak, 1989) are divided into eight regions (see Fig. 1; Table 1) following Wang and others (1995). The reason for using SIA time series as well as SIC time series is that many statistical methods require that a variable be random and independent, and SIA is a random variable, while the SIC $(1-10)$ is not.

\section{RESULTS: REGIONAL GHARACTERISTICS, SEASONALITY, INTERANNUAL AND INTER- DEGADAL VARIABILITY}

Monthly time series of SIAs in the eight regions are shown in Figure 2, with the interannual variability (using a 25 month moving average) superimposed in each region for the period 1901-95. The seasonal (or annual) cycle is a major phenomenon, but its effect differs according to region. For example, the boundary constraint (Wang and others, 1994) during winter is found in regions 2, 3 and 7, while summer ice-free conditions are found in regions 1 and 8.

The climatology of the seasonal cycle (Fig. 3) is computed based on the 1901-95 data (Fig. 2) for the eight regions. We observe four types of seasonality and interannual variability (Fig. 2, thick curves) in the SIA in the eight regions (Table 2). Type 1 (Bering Sea, Sea of Okhotsk) is characterized by no upper limit (of ice extent), but by a lower limit (i.e. ice-free conditions). By contrast, type 2 (Beaufort and Chukchi Seas, East Siberian and Laptev Seas) has an upper limit (due to boundary constraint) and no lower limit (because of summer ice or multi-year ice). Type 3 (Baffin Bay, Davis Strait and Labrador Sea, Greenland and Norwegian Seas, Barents and Kara Seas) has neither upper nor lower limit (no boundary constraint with multi-year ice) because of the open ocean. Type 4 (Hudson Bay) has both upper limit (boundary constraint) and lower limit (ice-free conditions) (Wang and others, 1994).

The corresponding monthly variations (standard deviations (STDs)) are also shown in Figure 3. The months with the largest STDs are those sensitive to atmospheric forcing and whose records are best for detecting interannual and decadal variability. For example, the largest STDs (Table 7, column titled 95 year STDs) occur in spring in regions 1 (16.14), 4 (13.23), 5 (12.22), 6 (19.49) and 8 (9.21), and in summer in regions 2 (23.88) and 7 (29.89). In region 4 (Hudson Bay), the STDs in spring, summer and autumn are comparable. In regions 4-6, the STDs for all four seasons are comparable (see Table 7, column titled 95 year STDs).

To clearly observe the interannual variability, the time series of SIA anomalies are calculated by removing the monthly climatology (Fig. 3) for each region (Fig. 4). SIA anomalies in all eight regions show a significant negative trend since the 1970s. This indicates that the sea-ice extent in most Arctic regions has been decreasing since then, although with a slightly different timing and magnitude for each region. The negative trend is associated with the intensifying positive phase of the AO (Thompson and others, 2000). Decadal oscillation is most pronounced in regions 

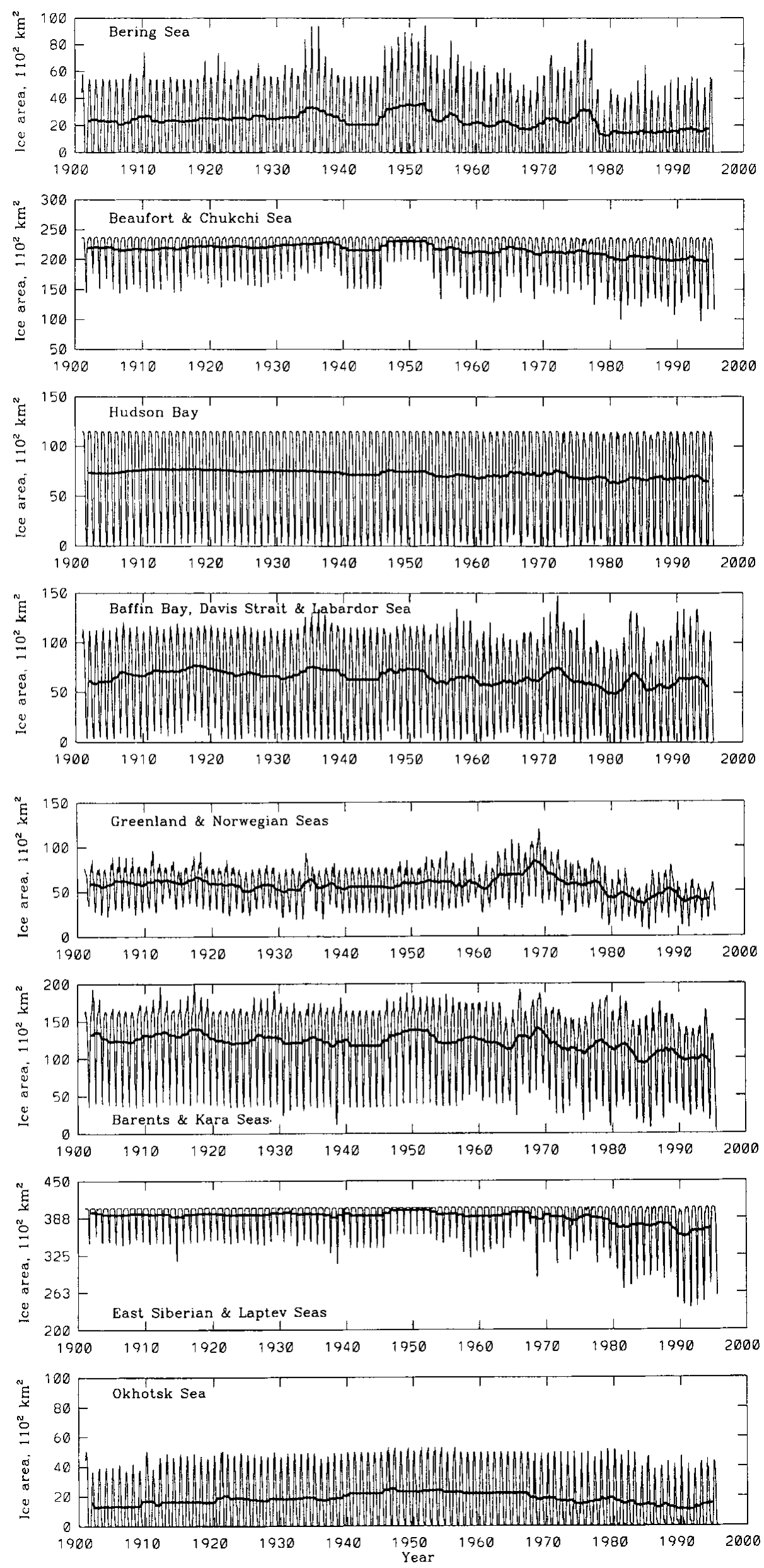

Fig. 2. Monthly time series of SIAs of the eight regions for the period 1901-95. The solid lines are the 25 month running means. 

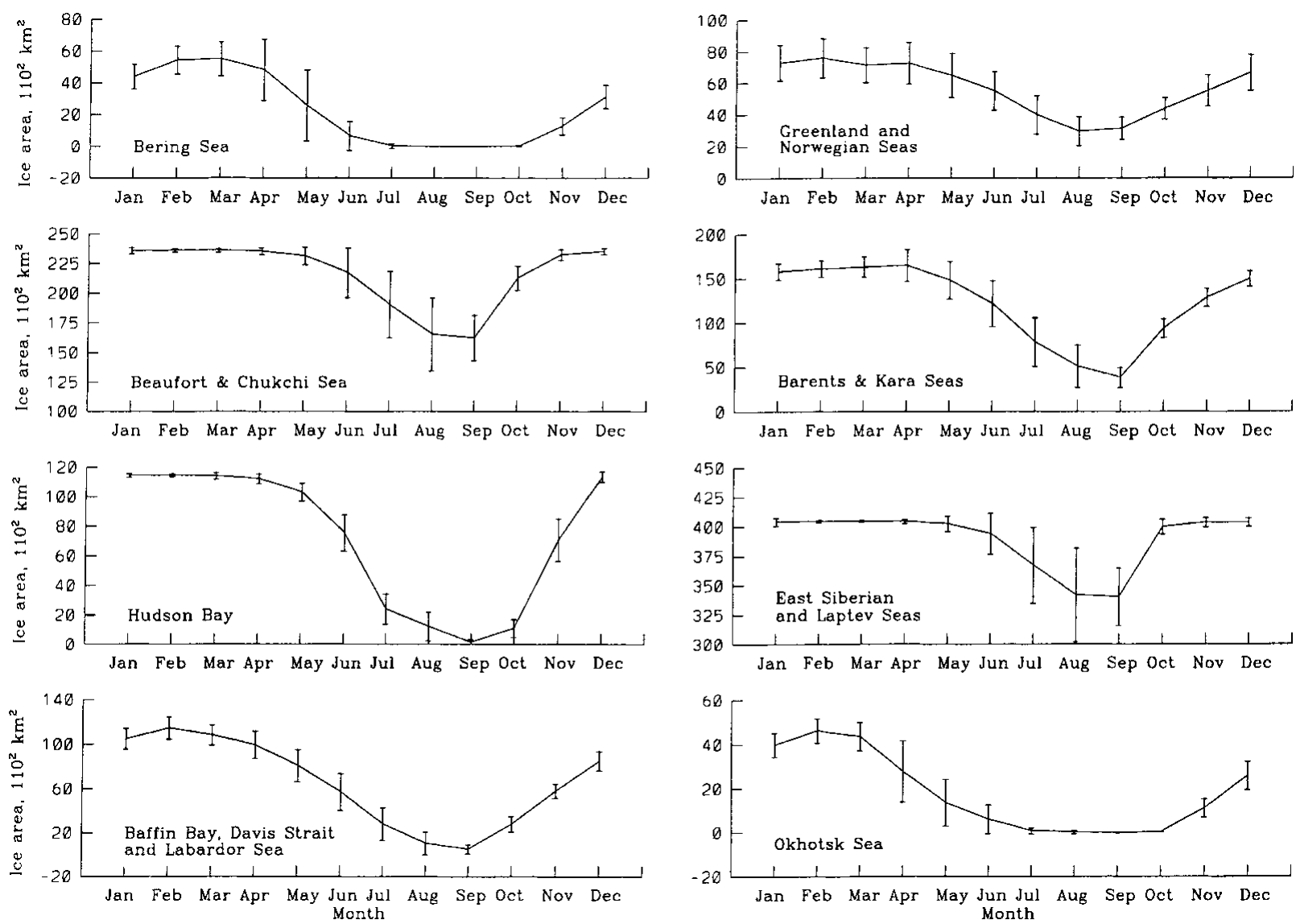

Fig. 3. The SIA monthly climatology with standard deviations (STDs) in the eight regions for the period 1901-95.

3-5 of the Atlantic sector (Häkkinen, 2000), and a century time-scale is most evident in region 8 (Sea of Okhotsk).

Considering the Arctic as a whole, the seasonal cycle and SIA and its anomaly (Fig. 5) show a similar trend of decreasing SIA since the 1970s. SIA reaches its maximum value of $1195 \times 110^{2} \mathrm{~km}^{2}$ in winter and its minimum value of $642 \times 110^{2} \mathrm{~km}^{2}$ in summer (with an annual mean of $964 \times 110^{2}$ $\mathrm{km}^{2}$ ). The largest variation occurs in summer (Fig. 5a; bottom row of Table 7), indicating that summer ice cover (or anomaly) can capture major interannual and decadal variability. These updated results indicate significant climate variability occurring in the Arctic region in the context of atmospheric circulation anomalies (Rogers, 1990;

\section{Table 2. Four types of seasonality and their characteristics and implication/indicator (by STDs) of long-term climate variability}

\begin{tabular}{|c|c|c|c|}
\hline & Regions & Characteristics & Variability/indicator \\
\hline Type 1 & 1,8 & $\begin{array}{l}\text { No upper limit; } \\
\text { lower limit }\end{array}$ & $\begin{array}{l}\text { STDs are higher in winter and } \\
\text { spring }\end{array}$ \\
\hline Type 2 & 2,7 & $\begin{array}{l}\text { Upper limit; no lower } \\
\text { limit (multi-year ice) }\end{array}$ & STDs are higher in summer \\
\hline Type 3 & $4,5,6$ & $\begin{array}{l}\text { Neither upper nor } \\
\text { lower limit }\end{array}$ & $\begin{array}{l}\text { STDs are comparable year- } \\
\text { round, and ocean plays a big role }\end{array}$ \\
\hline Type 4 & 3 & $\begin{array}{l}\text { Both upper and lower } \\
\text { limit }\end{array}$ & $\begin{array}{l}\text { STDs are higher in spring, early } \\
\text { summer and early fall. Break-up/ } \\
\text { freezing dates are good indicators }\end{array}$ \\
\hline
\end{tabular}

Note: Upper limit means land-boundary constraint in winter, and lower limit means ice-free conditions in summer.
Chapman and Walsh, 1993; Slonosky and others, 1997; MV98; TW98; Deser and others, 2000; Thompson and others, 2000; WI00).

\section{SPATIAL AND TEMPORAL PATTERNS OF ASIO}

The same unrotated EOF analysis package of Wang and others (1995) was applied to the demeaned, normalized SLP, SATand SIA for the period 1901-97 (sea ice only up to August 1995; see WI00) and for the period 1953-97. The principal modes of SIA and SAT anomalies are only discussed based on data from 1953-97.

The leading sea-ice mode (Fig. 6) accounts for $34 \%$ of the total variance. Sea-ice anomalies in the eight regions fluctuate in phase in response to the $\mathrm{AO}$, which has the same pattern as the SIA mode 1 derived from the data from 190195 (WI00). This ASIO pattern is consistent with the first SAT mode (Fig. 7), which shows a slight warming in most Arctic regions, particularly in northern Europe. From 1953 to 1977 , the Arctic sea ice had positive anomalies, while it experienced a decreasing phase during 1978-95. The time series obviously indicates a decrease in SIA since the 1970s, which is consistent with the total Arctic ice anomaly (Fig. 5c). It is noted that superimposed on the long-term trend since the 1970s are the decadal oscillations. The total Arctic ice-anomaly time series and the mode 1 temporal pattern are closely correlated (see the quantitative discussion below). Thus, this ASIO pattern that can be derived from the data of 1953-95 is similar to the results using data from 1901-95 (WI00).

The SIA anomaly mode 2 (Fig. 8) captures a dipolar or see- 

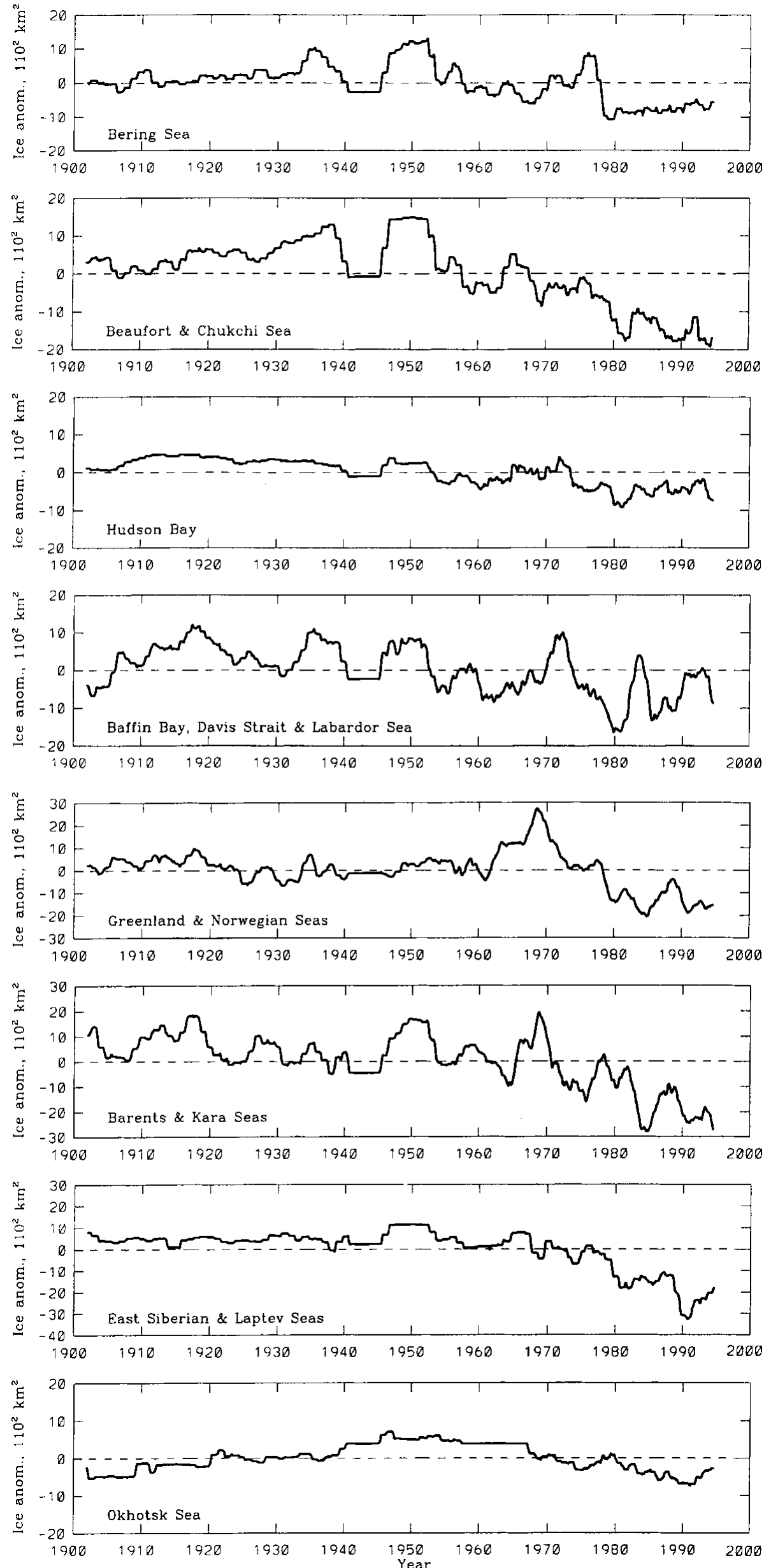

Fig. 4. Monthly SIA anomalies with the seasonal cycle (Fig. 3) removed. The 25 month running mean is applied. 

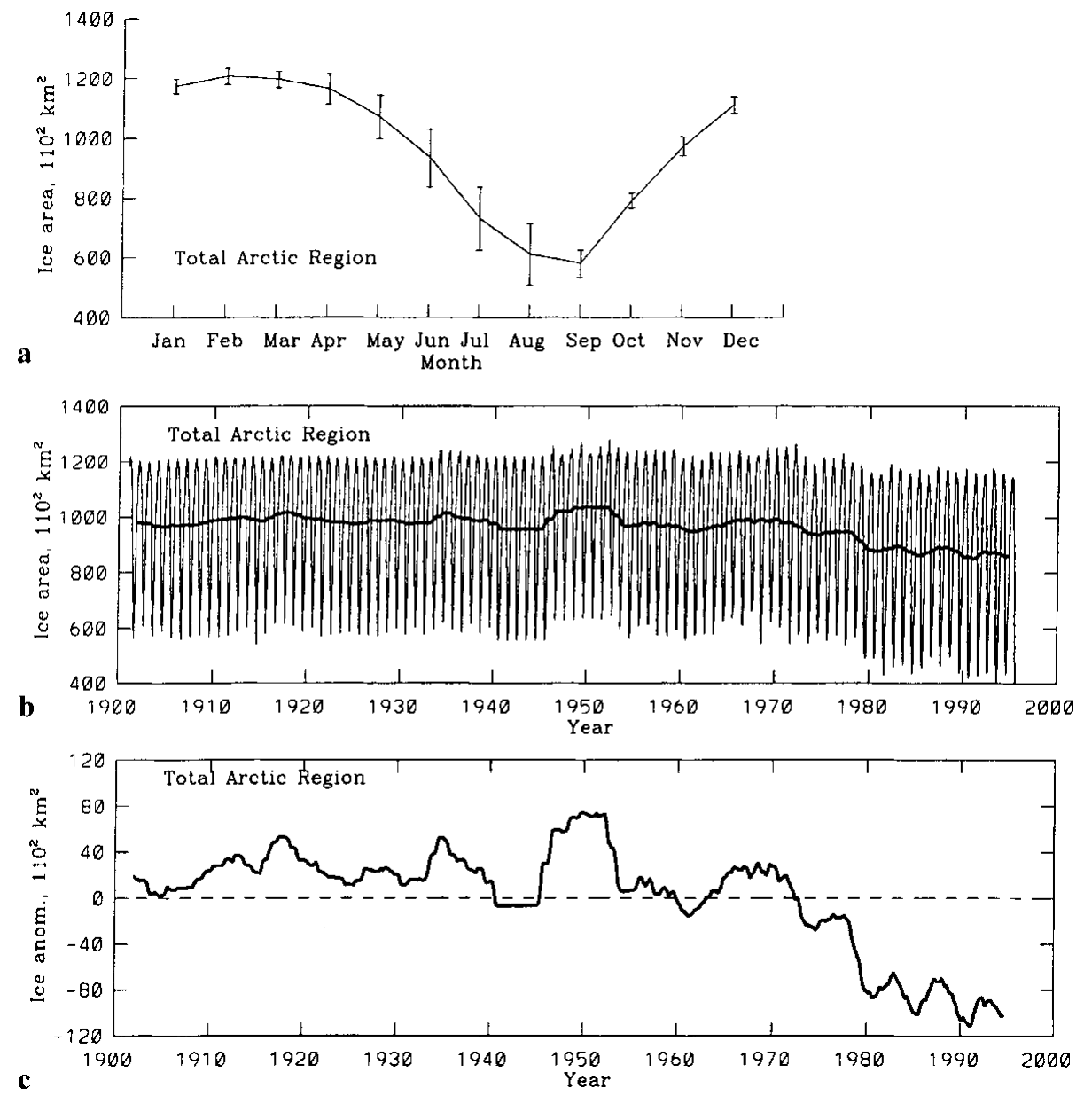

Fig. 5. The total Arctic sea ice: (a) seasonal cycle with standard deviations; (b) monthly time series of SIA with the 25 month running mean; (c) the SIA anomaly (25 month running mean) for the period 1901-95.
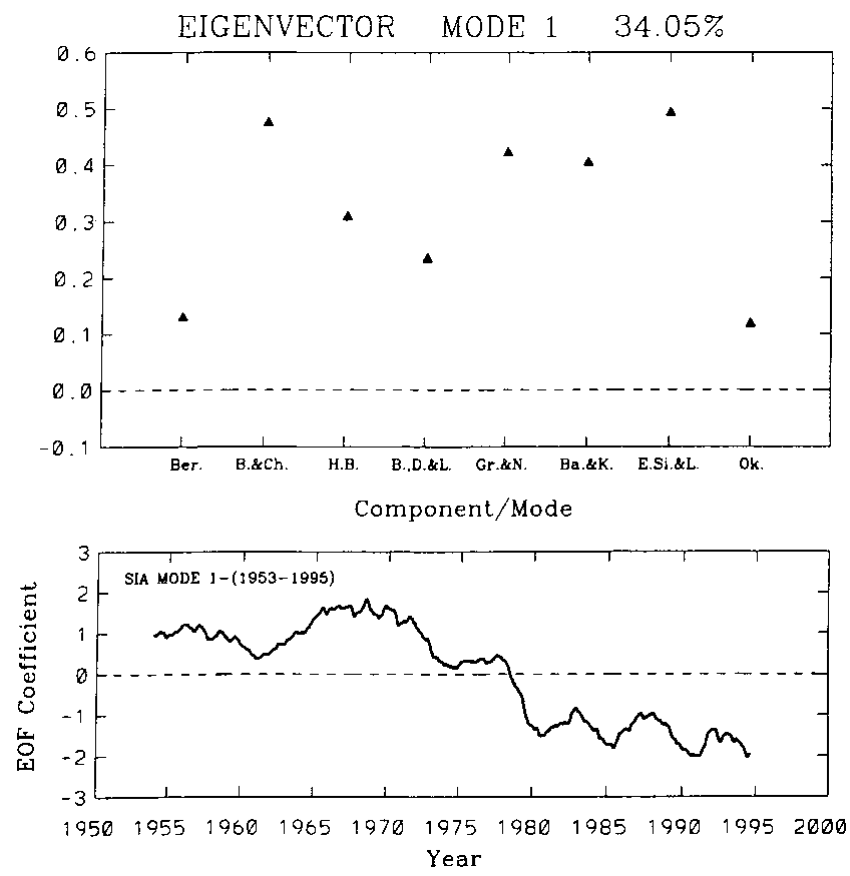

Fig. 6. The first leading EOF mode of the eigenvectors (spatial pattern, upper panel) and the time series of the eigenvalues or the coefficients (temporal pattern, lower panel) of SIA anomalies for the period 1953-95. The original (actual) spatial and temporal patterns of the anomalies of the mode can be reconstructed by multiplying the eigenvalues with the eigenvectors. saw pattern shown by the opposite sign (out of phase) between regions 3 and 4 (Hudson Bay and Baffin Bay-Labrador Sea) and regions 5 and 6 (Greenland and Norwegian Seas, and Barents and Kara Seas). This see-saw pattern is a reflection of the AO/NAO-related SATanomaly pattern (Wang and others, 1994; Mysak and others, 1996; Deser and others, 2000).

To quantitatively understand the two SIA patterns in the context of atmospheric circulation anomalies, we performed Monte Carlo simulations (Wang and others, 1994) of the SLP, SAT and SIA anomalies for the period 1953-97. Discussions are limited to those with a correlation of $>95 \%$ significance level (S.L.). The leading SLP mode (AO) correlates to SAT over all four seasons (Table 3, upper pair), indicating that the AO operates differently from the NAO, whose index correlates to the SATanomaly only in winter, spring and autumn (Mysak and others, 1996). Furthermore, the leading SAT mode (associated with the AO) correlates to the leading SIA mode (i.e. ASIO) over all four seasons (Table 3, middle pair). The significant correlation between the summer SLP and SIA (Table 3, lower pair) occurs only in spring $(r=0.36)$ and summer $(r=0.26)$, implying that wind (an AO-related SLP anomaly) driving of the SIA (through advection, convergence and divergence) is most effective in spring and summer, when there are open waters, resulting in sea-ice thickness redistribution and sea-ice flux out of the Arctic Ocean (Kwok and Rothrock, 1999; Rothrock and others, 1999). The correlation coefficients (Table 3) are generally larger than those using the longer dataset (WI00).

To reveal the features of SIA mode 2, the leading SAT- 
EIGENVECTOR MODE $1,14.1 \%$

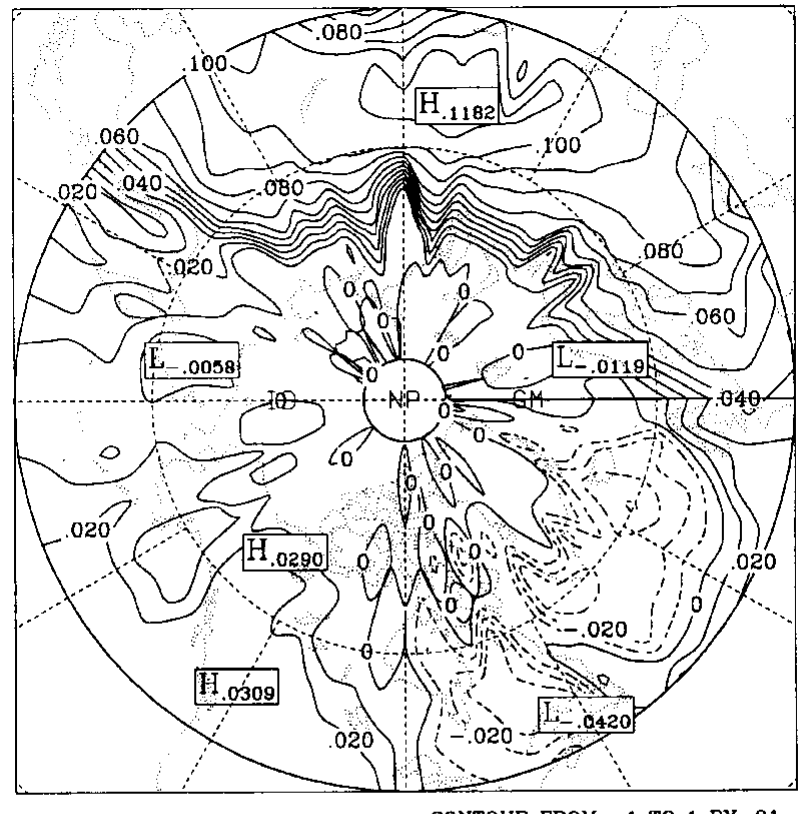

CONTOUR FROM -1 TO 1 BY .01

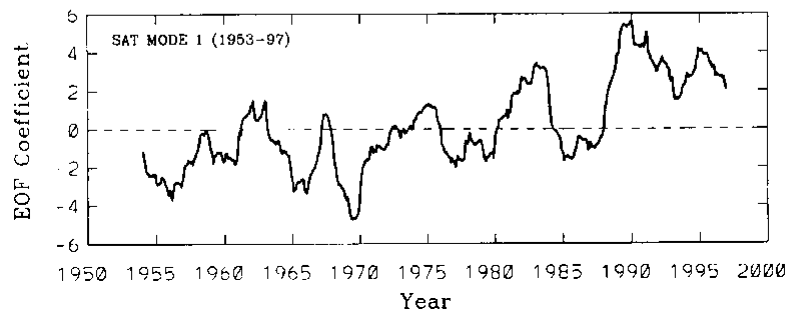

Fig. 7. Same as Figure 6, except for the SAT anomalies.
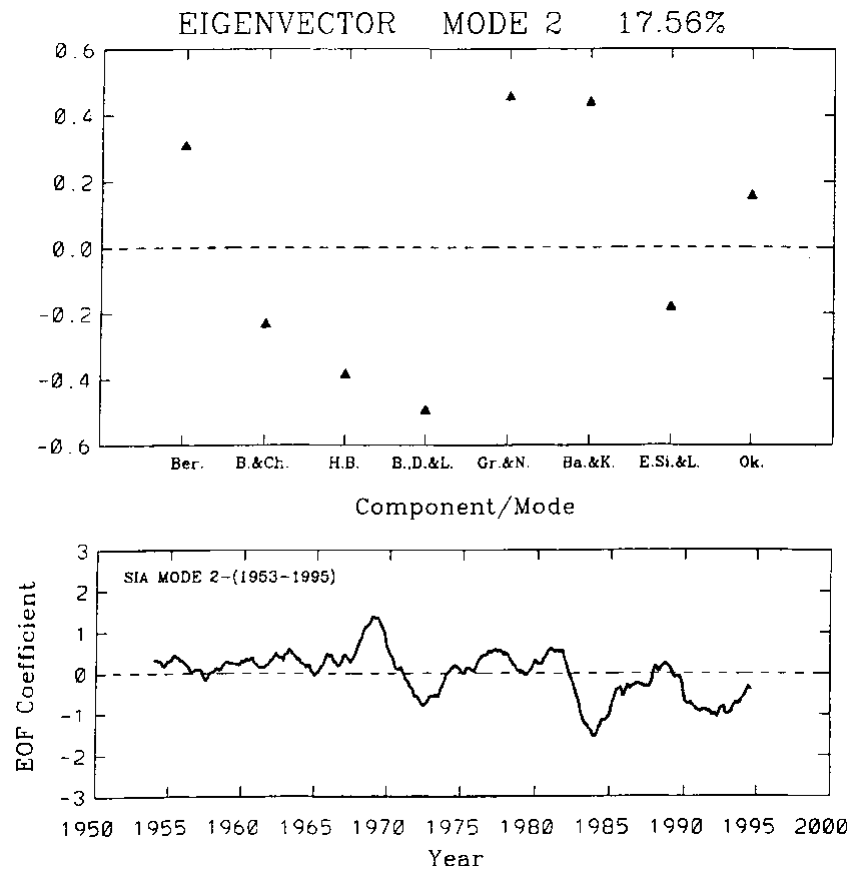

Fig. 8. Same as Figure 6, except for the second EOF mode for SIA anomalies.

and SLP-mode time series were linearly regressed to the SIA mode 2 time series (Table 4). It is clear that SAT mode 1 negatively correlates SIA anomalies in both winter $(r=-0.57)$ and spring $(r=-0.44)$, although the positive correlation in summer may not be physically meaningful. Similarly, the
Table 3. Simultaneous and lagged correlation coefficients ( $r$, with 95\% S.L. derived from a Monte Carlo simulation) between the annual SLP (the leading/AO) mode and the SAT mode (upper pair; for the period 1953-97); between the annual SAT and SIA ( ASIO) (leading) modes (middle pair; 1953-95); and between the annual SLP and SIA (leading) modes (lower pair; 1953-95)

\begin{tabular}{|c|c|c|c|c|c|}
\hline & Winter & Spring & Summer & Autumn & Annual \\
\hline \multicolumn{6}{|c|}{ Annual SLP and SAT (mode 1) } \\
\hline$r$ & -0.68 & -0.64 & -0.50 & -0.51 & -0.77 \\
\hline 95\% S.L. & 0.25 & 0.25 & 0.25 & 0.25 & 0.25 \\
\hline \multicolumn{6}{|c|}{ Annual SAT and SIA (mode 1) } \\
\hline$r$ & -0.49 & -0.59 & -0.54 & -0.37 & -0.56 \\
\hline 95\% S.L. & 0.27 & 0.28 & 0.27 & 0.26 & 0.27 \\
\hline \multicolumn{6}{|c|}{ Annual SLP and SIA (mode 1) } \\
\hline$r$ & 0.24 & 0.36 & 0.26 & 0.18 & 0.29 \\
\hline 95\% S.L. & 0.26 & 0.25 & 0.25 & 0.25 & 0.25 \\
\hline
\end{tabular}

Note: The coefficients over 95\% S.L. are boldfaced.

Table 4. Same as Table 3, except the leading SAT mode (upper pair) and leading SLP mode (lower pair) linearly regress to SIA mode 2

\begin{tabular}{|c|c|c|c|c|c|}
\hline & Winter & Spring & Summer & Autumn & Annual \\
\hline \multicolumn{6}{|c|}{ Annual SAT (mode 1) and SIA (mode 2) } \\
\hline$r$ & -0.57 & -0.44 & 0.31 & -0.20 & -0.37 \\
\hline $95 \%$ S.L. & 0.27 & 0.27 & 0.25 & 0.25 & 0.25 \\
\hline \multicolumn{6}{|c|}{ Annual SLP (mode 1) and SIA (mode 2) } \\
\hline$r$ & 0.40 & 0.31 & -0.04 & 0.13 & 0.30 \\
\hline 95\% S.L. & 0.26 & 0.25 & 0.25 & 0.25 & 0.25 \\
\hline
\end{tabular}

Note: The coefficients $(r)$ over 95\% S.L. (using a Monte Carlo simulation) are boldfaced.

Table 5. Same as Table 3, except that the leading SIA mode (upper pair), leading SAT mode (middle pair) and leading SLP mode (lower pair) linearly regress to the total Arctic SIA anomaly (SIA A )

\begin{tabular}{|c|c|c|c|c|c|}
\hline & Winter & Spring & Summer & Autumn & Annual \\
\hline \multicolumn{6}{|c|}{ Annual SIA mode 1 and SIAA } \\
\hline$r$ & 0.83 & 0.83 & 0.81 & 0.88 & 0.90 \\
\hline $95 \%$ S.L. & 0.44 & 0.43 & 0.42 & 0.42 & 0.44 \\
\hline \multicolumn{6}{|c|}{ Annual SAT mode 1 and SIAA } \\
\hline$r$ & -0.38 & -0.54 & -0.43 & -0.42 & -0.48 \\
\hline 95\% S.L. & 0.27 & 0.28 & 0.27 & 0.26 & 0.27 \\
\hline \multicolumn{6}{|c|}{ Winter SLP mode 1 and SIAA } \\
\hline$r$ & 0.18 & 0.31 & 0.22 & 0.26 & 0.26 \\
\hline 95\% S.L. & 0.27 & 0.25 & 0.26 & 0.26 & 0.25 \\
\hline
\end{tabular}

Note: The coefficients $(r)$ over 95\% S.L. (using a Monte Carlo simulation) are boldfaced.

leading SLP mode positively correlates to the SIA anomaly in both winter $(r=0.40)$ and spring $(r=0.31)$, while the other seasons are not significant (Mysak and others, 1996). This clearly indicates an AO/NAO-related SAT see-saw pat- 
Periods in years

Periods in years
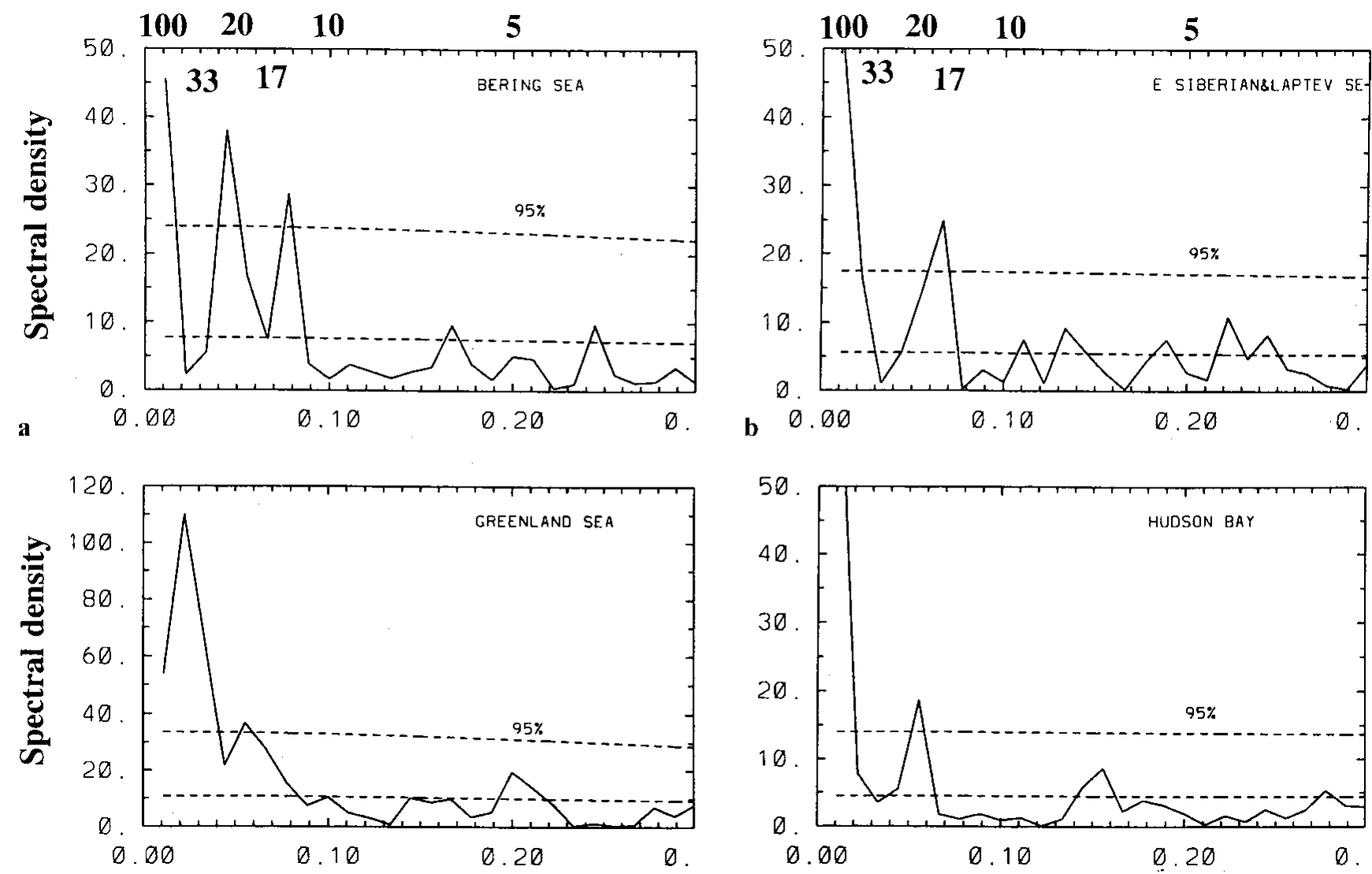

c

Cycles per year

d

Cycles per year

Fig. 9. The auto-spectrum (solid curve) of the time series of the SIA anomalies for the period 1901-95 in the Bering Sea (a), the East Siberian and Laptev Seas (b), the Greenland and Norwegian Seas (c) and Hudson Bay (d). The upper (lower) dashed curve denotes the $95 \%$ confidence limit (red-noise spectrum). Since the time series have been normalized by their own standard deviations, the units of the spectra are in period in years $(a, b)$ or cycles per year $(c, d)$.

tern (Wang and others, 1994; Mysak and others, 1996; Deser and others, 2000).

Further linearly regressing the leading SIA, SATand SLP modes to the total Arctic SIA anomaly (Table 5) results in correlation coefficients between the leading SIA mode and SIA anomaly all above 0.8 (Table 5 , upper pair). The correlations between the leading SAT mode and SIA anomaly are also high (middle pair). However, only the winter time series of the leading SLP mode significantly correlates to the spring-summer-autumn SIA anomalies $(r=0.3,0.22,0.26$, respectively). The summer correlation $(r=0.22)$ is not significant but is close to the $95 \%$ significance level of 0.26 .

Finally, the leading SIA-mode (ASIO) time series was linearly regressed to the SIA anomaly of each region (Table 6, upper pair). SIA anomalies in all regions are significantly correlated to the leading SIA mode, except region 4 (Baffin Bay, Davis Strait and the Labrador Sea). However, the SIA anomaly for region 4 does exhibit a close correlation $(0.32$ compared to its $95 \%$ significance level of 0.35 ) with the leading SIA mode. Similarly, the second SIA-mode time series was linearly regressed to the SIA anomaly of each region (Table 6, lower pair). A dipolar or see-saw pattern can be captured between regions 3 and 4 and regions 5 and 6, consistent with the composite analysis of the SAT see-saw pattern of the NAO (Wang and others, 1994).

In summary, two major modes for the Arctic SIA anomaly can be extracted using the EOF analysis. The leading SIA mode is the AO-intensifying-trend-related mode, which has an in-phase (or spatially uniform) structure (Deser and others, 2000; Häkkinen, 2000; WI00; Ikeda and others, 2001). The second SIA mode shows a dipolar or see-saw structure in the Atlantic sector, which is also AO/NAO-related (Häkkinen and Geiger, 2000) like the winter sea-ice variation pattern of Deser and others (2000). Significant evidence for the AO mode can be found in the oceanographic data. Steele and Boyd (1998) found that the cold halocline layer in the Arctic Ocean retreated from the decade 1979-87 to the decade 198896 , indicating the significant effect of the AO on the ocean

Table 6. Annual leading SIA mode (upper pair) and second SIA mode (lower pair) linearly regress to the total Arctic SIA anomaly (SIA A) and all eight regions

SIA_A Reg_1 Reg_2 Reg_3 Reg_4 Reg_5 $\operatorname{Reg}_{-6}$ Reg_7 Reg_8

\begin{tabular}{lrrrllllll}
\hline$r$ & $\mathbf{0 . 9 0}$ & $\mathbf{0 . 5 3}$ & $\mathbf{0 . 7 0}$ & $\mathbf{0 . 5 4}$ & 0.32 & $\mathbf{0 . 8 8}$ & $\mathbf{0 . 7 0}$ & $\mathbf{0 . 8 4}$ & $\mathbf{0 . 7 6}$ \\
$95 \%$ S.L. & 0.44 & 0.38 & 0.41 & 0.31 & 0.35 & 0.46 & 0.37 & 0.42 & 0.45 \\
$r$ & $\mathbf{- 0 . 4 2}$ & -0.25 & -0.17 & 0.20 & $\mathbf{0 . 4 0}$ & $\mathbf{- 0 . 6 6}$ & $\mathbf{- 0 . 7 1}$ & $\mathbf{- 0 . 3 4}$ & $\mathbf{- 0 . 4 6}$ \\
$95 \%$ S.L. & 0.28 & 0.27 & 0.28 & 0.25 & 0.25 & 0.28 & 0.28 & 0.27 & 0.27
\end{tabular}

Note: The coefficients $(r)$ over $95 \%$ S.L. (using a Monte Carlo simulation) are boldfaced. 


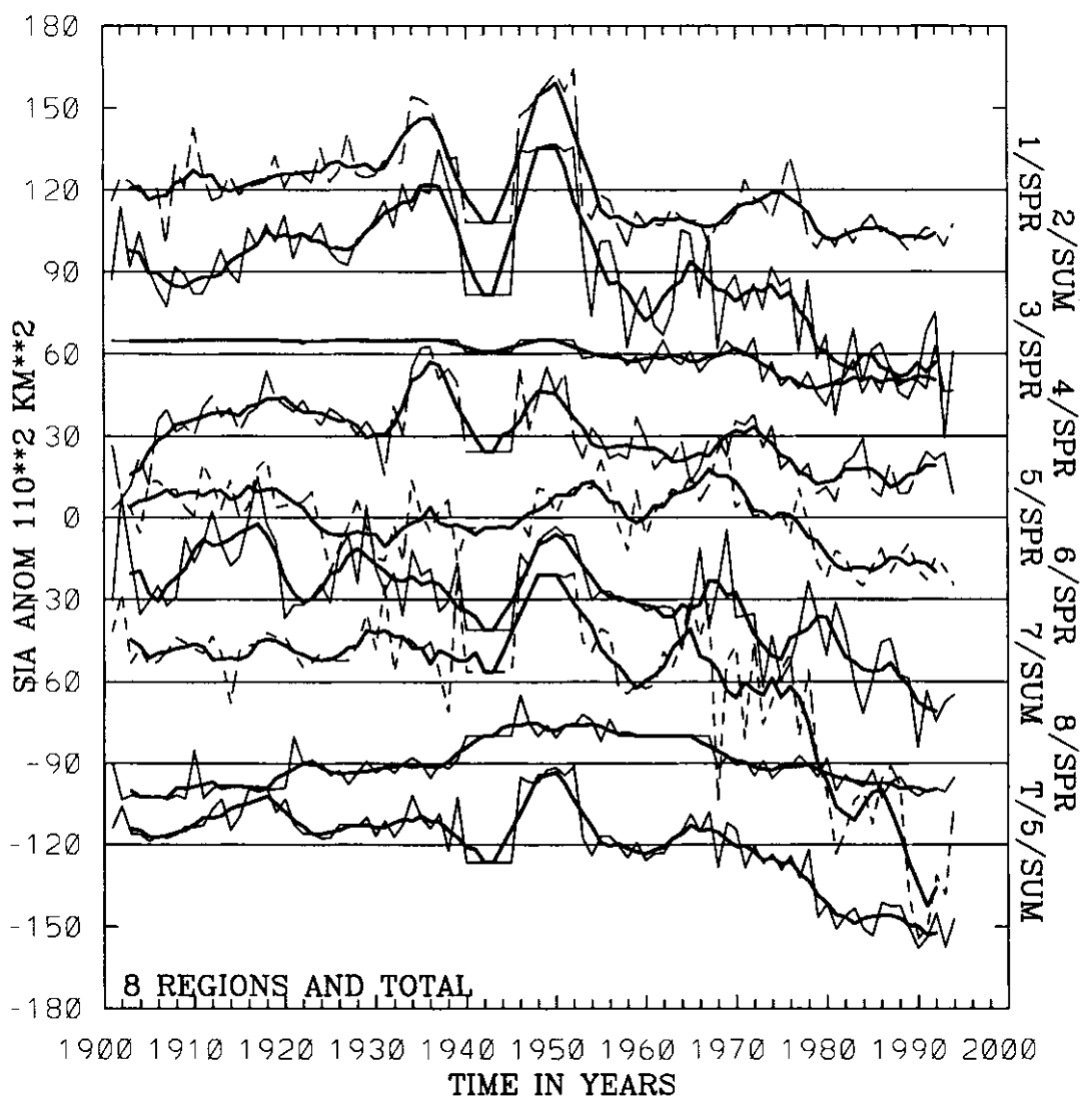

Fig. 10. Annual averaged time series of the most sensitive seasons for the eight regions and the total Arctic seas. The thick lines denote the 5 year running means. The vertical coordinate is relative with an interval of $30 \times 110^{2} \mathrm{~km}^{2}$, and the total Arctic SIA anomaly has been divided by a factor of 5 .

thermodynamics. Also, during 1979-87, the sea-ice anticyclonic circulation (i.e. the Beaufort Gyre) was much stronger than its counterpart during 1988-96, because the decreasing SLP (cyclonic anomaly) during the 1990s weakened the Beaufort High, which in turn was caused by the intensifying positive phase of the AO.

Next, we examine the spectral characteristics of the 95 year SIA time series from the four types of regions (Fig. 9). There are three major time-scales in the Bering Sea (type 1): about 12.5 years, 20 years and $>50 />70$ years (Minobe, 1997; Zhang and others, 1997). In the East Siberian and Laptev Seas (type 2), two major time-scales are 14-18 years and $>70$ years. In the Greenland and Norwegian Seas (type 3), there are 18 year (Ikeda, 1990; Mysak and others, 1990) and > 50 year periods (Delworth and others, 1997). In Hudson Bay (type 4), major time-scales include an 18 year period and another period of $>50$ years. Regions 3 and 4 are correspondingly correlated in the see-saw regions (Wang and others, 1994; Mysak and others, 1996).

Overall, there are three major time-scales: $12-14$ years (Häkkinen, 2000; Hilmer and Lemke, 2000), 17-20 years and $>50 />70$ years (which is probably the century time-scale). The $>50$ year (probably 100 years and longer) time-scales are evident from the time series of the total Arctic SIA anomaly, as well as from the time series of SIAs in the eight regions (see Figs 4 and 5). In particular, a century time-scale is evident in the Sea of Okhotsk (if the records are as good in the first half of the 20th century as in the second half). Longer time series or their proxies are needed to verify this $>50 /$ $>70$ year time-scale of sea-ice anomalies in the Arctic.

\section{STATISTICS AND ANNUAL AND SEASONAL SIA TRENDS IN THE LAST THREE DEGADES}

ASIO may consist of two variations in response to AO. One responds to an AO-intensifying trend (Thompson and others, 2000), and the other to AO/NAO-related atmosphere-ice-ocean interactions (positive feedback triggered by reduced ice thickness in the Arctic) over the Atlantic sector (Ikeda, 1990; Wang and others, 1994; Mysak and others, 1996; Ikeda and others, 2001). In this section, we examine the SIA trends (Vinnikov and others, 1999; Vinje, 2001) over the last three decades in terms of annual and seasonal characteristics in both regional (all eight regions) and global (total Arctic sea-ice cover character) views.

Figure 10 shows annual time series of the most sensitive seasons (spring and summer) for all eight regions and the total Arctic seas. The trends since 1970 are remarkable, varying from region to region, with the interannual and decadal variability superimposed.

Table 7 shows the seasonal statistics and trends from 1970 to 1994. High STDs usually occur in either spring or summer, as do the negative trends. Note that although summer negative trends in some regions (regions 3, 4, 6, 8) are large, their seasonal contributions to the annual trends may be relatively small, because their summer means are smaller than the means of other seasons. Their relative contribution to the annual SIA anomalies can be obtained (Table 7, rightmost column) by multiplying a factor, $F=a_{i} / \sum_{i} a_{i}$ (where $i=$ 1, 2, 3 and 4, representing four seasons, and $a$ is the SIA).

Table 8 depicts the annual statistics, trends and relative 
Wang and Ikeda: Arctic sea-ice oscillation

Table 7. Seasonal statistics of 95 year SIA data, trends from 1970 to 1994, and the relative seasonal contribution (rightmost column) to the annual trend of each region (Table 8 , rightmost column). Units are $110^{2} \mathrm{~km}^{2}$

\begin{tabular}{|c|c|c|c|c|c|c|c|c|}
\hline \multicolumn{2}{|c|}{ Region/Seasons } & \multirow{2}{*}{$\begin{array}{c}95 \text { year mean, } x_{i} \\
51.29\end{array}$} & \multirow{2}{*}{$\begin{array}{c}95 \text { year STDs } \\
7.73\end{array}$} & \multirow{2}{*}{$\begin{array}{c}\text { SIA_A_1970 } \\
3.97\end{array}$} & \multirow{2}{*}{$\begin{array}{l}S I A \_A \_1994 \\
-12.76\end{array}$} & \multirow{2}{*}{$\begin{array}{l}\text { Trend decade }{ }^{-1} \\
-13.0 \%\end{array}$} & \multirow{2}{*}{$\frac{F=x_{i} / \sum_{i} x_{i}, i=1, \ldots 8}{54.73 \%}$} & \multirow{2}{*}{$\begin{array}{c}F \times \text { Trend decade }^{-1} \\
-7.15 \%\end{array}$} \\
\hline 1 & $\mathrm{~W}$ & & & & & & & \\
\hline & $\mathrm{S}$ & 27.28 & 16.14 & -8.21 & -12.48 & $-6.3 \%$ & $29.11 \%$ & $-1.83 \%$ \\
\hline & $\mathrm{S}$ & 0.18 & 0.48 & -0.18 & -0.18 & $0.0 \%$ & $0.19 \%$ & $0.00 \%$ \\
\hline & A & 14.96 & 3.92 & -3.53 & 2.44 & $16.0 \%$ & $15.96 \%$ & $2.55 \%$ \\
\hline \multirow[t]{4}{*}{2} & $\mathrm{~W}$ & 236.33 & 1.34 & -1.99 & -0.68 & $0.2 \%$ & $27.31 \%$ & $0.05 \%$ \\
\hline & $\mathrm{S}$ & 228.53 & 9.38 & -12.33 & -11.43 & $0.2 \%$ & $26.41 \%$ & $0.05 \%$ \\
\hline & $\mathrm{S}$ & 173.33 & 23.88 & -1.26 & -29.30 & $-6.5 \%$ & $20.03 \%$ & $-1.30 \%$ \\
\hline & A & 227.03 & 4.77 & 6.27 & -2.50 & $-1.5 \%$ & $26.24 \%$ & $-0.39 \%$ \\
\hline \multirow[t]{4}{*}{3} & $\mathrm{~W}$ & 114.44 & 8.59 & 0.5 & -0.77 & $-0.4 \%$ & $39.53 \%$ & $-0.16 \%$ \\
\hline & $\mathrm{S}$ & 97.15 & 13.23 & 1.19 & -13.45 & $-6.0 \%$ & $33.55 \%$ & $-2.01 \%$ \\
\hline & $\mathrm{S}$ & 12.79 & 8.75 & -3.22 & -10.25 & $-2.2 \%$ & $4.42 \%$ & $-0.97 \%$ \\
\hline & A & 65.15 & 5.81 & 13.51 & -12.65 & $-16.1 \%$ & $22.50 \%$ & $-3.62 \%$ \\
\hline \multirow[t]{4}{*}{4} & $\mathrm{~W}$ & 109.39 & 8.59 & 2.24 & 1.04 & $-0.4 \%$ & $41.94 \%$ & $-0.17 \%$ \\
\hline & $\mathrm{S}$ & 79.5 & 13.23 & 5.6 & -21.64 & $-13.7 \%$ & $30.48 \%$ & $-4.18 \%$ \\
\hline & $\mathrm{S}$ & 14.79 & 8.75 & 5.38 & -11.99 & $-47.0 \%$ & $5.67 \%$ & $-2.67 \%$ \\
\hline & A & 57.12 & 5.81 & 6.75 & -4.79 & $-8.1 \%$ & $21.90 \%$ & $-1.77 \%$ \\
\hline \multirow[t]{4}{*}{5} & $\mathrm{~W}$ & 73.71 & 10.69 & 20.42 & -26.11 & $-25.3 \%$ & $32.46 \%$ & $-8.21 \%$ \\
\hline & $\mathrm{S}$ & 64.44 & 12.22 & 3.93 & -24.77 & $-34.1 \%$ & $28.38 \%$ & $-9.68 \%$ \\
\hline & $\mathrm{S}$ & 33.71 & 8.69 & 12.89 & -9.21 & $-26.2 \%$ & $14.84 \%$ & $-3.89 \%$ \\
\hline & A & 55.24 & 8.74 & 10.32 & -6.84 & $-12.4 \%$ & $24.32 \%$ & $-3.02 \%$ \\
\hline \multirow[t]{4}{*}{6} & $\mathrm{~W}$ & 161.28 & 8.47 & 0.12 & 0.65 & $0.1 \%$ & $33.06 \%$ & $0.03 \%$ \\
\hline & $\mathrm{S}$ & 145.82 & 19.49 & -6.62 & -34.79 & $-7.7 \%$ & $29.89 \%$ & $-2.30 \%$ \\
\hline & $\mathrm{S}$ & 56.49 & 17.93 & 1.67 & -30.19 & $-22.6 \%$ & $11.58 \%$ & $-2.62 \%$ \\
\hline & A & 124.27 & 7.93 & 7.46 & -8.87 & $-5.3 \%$ & $25.47 \%$ & $-1.35 \%$ \\
\hline \multirow[t]{4}{*}{7} & $\mathrm{~W}$ & 404.64 & 1.43 & 0.19 & 0.03 & $0.0 \%$ & $25.97 \%$ & $0.00 \%$ \\
\hline & $\mathrm{S}$ & 400.58 & 7.88 & 0.82 & -14.88 & $-1.6 \%$ & $25.71 \%$ & $-0.41 \%$ \\
\hline & $\mathrm{S}$ & 350.54 & 29.89 & 12.96 & -44.54 & $-6.6 \%$ & $22.50 \%$ & $-1.48 \%$ \\
\hline & A & 402.50 & 3.41 & 2.47 & 0.44 & $-0.2 \%$ & $25.83 \%$ & $-0.05 \%$ \\
\hline \multirow[t]{4}{*}{8} & $\mathrm{~W}$ & 43.26 & 4.78 & -4.12 & -3.09 & $1.0 \%$ & $59.90 \%$ & $0.60 \%$ \\
\hline & $\mathrm{S}$ & 16.02 & 9.21 & 1.51 & -5.12 & $-16.6 \%$ & $22.18 \%$ & $-3.68 \%$ \\
\hline & $\mathrm{S}$ & 0.44 & 0.67 & -0.14 & 0 & $12.7 \%$ & $0.61 \%$ & $0.08 \%$ \\
\hline & A & 12.50 & 3.01 & 1.57 & -3.10 & $-14.9 \%$ & $17.31 \%$ & $-2.58 \%$ \\
\hline \multirow[t]{4}{*}{$\mathrm{Ttl}$} & W & 1194.3 & 23.74 & 21.33 & -41.70 & $-2.1 \%$ & $30.98 \%$ & $-0.65 \%$ \\
\hline & $\mathrm{S}$ & 1059.32 & 69.53 & -14.12 & -138.55 & $-4.7 \%$ & $27.48 \%$ & $-1.29 \%$ \\
\hline & $\mathrm{S}$ & 642.27 & 78.97 & 28.09 & -135.67 & $-10.2 \%$ & $16.66 \%$ & $-1.70 \%$ \\
\hline & A & 958.78 & 25.54 & 44.82 & -35.88 & $-3.4 \%$ & $24.87 \%$ & $-0.85 \%$ \\
\hline
\end{tabular}

Notes: Winter (W), spring (S), summer (S) and autumn (A) months are January-March, April-June, July-September and October-December, respectively.

Maximum values in the region are boldfaced.

regional contributions to the total Arctic sea-ice change. In the last three decades (1970-94), the negative trend of the total Arctic sea-ice extent is $-4.5 \%$ per decade. This can be simulated by a coupled ice- - ocean model $(-4 \%$ per decade;
Hilmer and Lemke, 2000). The negative trends vary from region to region. The relative regional contributions to the total Arctic trend can be listed as follows, in order of magnitude (Table 8, rightmost two columns): regions 5

Table 8. Annual statistics of 95 year SIA data, trends from 1970 to 1994, and the relative regional contribution (sixth and last columns) to the total Arctic sea-ice trend of $-4.5 \%$ per decade. Units are $110^{2} \mathrm{~km}^{2}$

\begin{tabular}{|c|c|c|c|c|c|c|c|}
\hline Region & 95 year mean, $x_{i}$ & 95 year $S T D$ s & SIA_A_1970 & $S I A \_A \_1994$ & Trend decade $e^{-1}$ & $F=x_{i} / \sum_{i} x_{i}, i=1, \ldots 8$ & $F \times$ Trend decade $e^{-1}$ \\
\hline 1 & 23.43 & 5.72 & -1.99 & -5.75 & $-13.2 \%$ & $2.43 \%$ & $-0.22 \%$ \\
\hline 3 & 72.38 & 3.98 & 2.99 & -9.28 & $-6.8 \%$ & $7.51 \%$ & $-0.51 \%$ \\
\hline 4 & 65.20 & 6.77 & 4.99 & -9.43 & $-8.8 \%$ & $6.77 \%$ & $-0.60 \%$ \\
\hline 5 & 56.78 & 8.89 & 11.89 & -16.73 & $-20.2 \%$ & $5.89 \%$ & $-1.19 \%$ \\
\hline 6 & 121.97 & 11.30 & 0.66 & -18.30 & $-6.2 \%$ & $12.66 \%$ & $-0.78 \%$ \\
\hline 7 & 389.56 & 9.74 & 4.11 & -14.74 & $-1.9 \%$ & $40.42 \%$ & $-0.77 \%$ \\
\hline 8 & 18.05 & 3.71 & -0.29 & -2.83 & $-5.6 \%$ & $1.87 \%$ & $-0.10 \%$ \\
\hline Total & 963.68 & 46.03 & 20.03 & -87.95 & $-4.5 \%$ & & \\
\hline
\end{tabular}

Note: Maximum values in the column are boldfaced. 
$(-1.19 \% /-20.2 \%), 6(-0.78 \% /-6.2 \%), 7$ (-0.77\%/-1.9\%), 3 $(-0.51 \% /-6.8 \%)$, and $2(-0.43 \% /-1.2 \%)$, in terms of relative/absolute reduction rate (percentage per decade), although the large absolute reduction rate occurs in regions $1(-13.2 \%)$ and $8(-5.6 \%)$ (see Table 8 , sixth column). The regional reduction rate of $-20.0 \%$ per decade is largest in the Greenland and Norwegian Seas (region 5).

\section{GONGLUSION AND DISGUSSION}

Four types of seasonality of sea-ice variations were categorized (Table 2). Type 1 (Bering Sea, Sea of Okhotsk) has nearly zero variability (standard deviation) in summer and large variability in winter, with no boundary limit of the SIA. Type 2 (Beaufort and Chukchi Seas, East Siberian and Laptev Seas) has the largest variability in summer without any limit and has the smallest variability in winter with SIA limited by the land-boundary constraint. Type 3 (Baffin Bay-Labrador Sea, Greenland and Norwegian Seas, Barents and Kara Seas) has comparable year-round variability, with summer ice STD being largest and without land-boundary constraint. The ocean circulation and its heat transport have the strongest impact on the sea-ice pattern in these regions. Type 4 (Hudson Bay) has nearly zero ice area in summer and the strongest land-boundary constraint in winter, so variability is stronger in spring and autumn. Therefore, investigation of spring break-up time and fall freezing dates will help predict the summer and winter ice conditions in Hudson Bay. Sea-ice thickness must be used to detect the wintertime ice conditions and ice volume in those regions with land constraint, such as regions 2, 3 (Wang and others, 1994) and 7.

Arctic sea-ice extent has experienced a negative trend since the $1970 \mathrm{~s}(-4.5 \%$ per decade), with the largest trend occurring in summer $(-10.2 \%$ per decade). This corresponds to the intensifying $\mathrm{AO}$ events that result in a warming of northern Europe and the central Arctic (Thompson and others, 2000; WI00). All eight regions experience deduction rates ranging from $-1.6 \%$ to $-20.2 \%$ per decade (Table 8 , sixth column), with those in region 5 (the Greenland and Norwegian Seas) being the highest $(-20.2 \%$ per decade).

In terms of SIA anomaly, two major EOF modes were extracted, which physically correspond to the AO/NAO. The ASIO shows the in-phase decrease in sea-ice thickness/ice cover, superimposed by the decadal oscillations in response to the intensifying AO-related SAT pattern (WI00; Ikeda and others, 2001). The other pattern has a dipolar structure (the see-saw regions) between regions 3 and 4 and regions 5 and 6 in the Atlantic sector (Wang and others, 1994; see their figs 6 and 7).

In addition to the interannual time-scales, the major decadal and interdecadal time-scales were also found for the Arctic sea-ice areas: 12-14 and 17-20 years for the four types of regions (Mysak and others, 1990; Häkkinen, 2000; Häkkinen and Geiger, 2000; Hilmer and Lemke, 2000). Longer SIA time series or their proxies are needed to verify the $>50 />70$ year (Delworth and others, 1997; Minobe, 1997) and century time-scales (Tremblay and others, 1997). In the North Pacific sector, Minobe (1997) found the 50-70 year periods in the North Pacific Oscillation using SLP, SAT, seasurface temperature and tree-ring data. In the Atlantic sector, Ikeda (1990) proposed that the air-ice-ocean system is essential for the decadal oscillation. Mysak and others (1990) also found interdecadal variability in sea-ice extent and linked it, by a hypothesized feedback loop, to the Great Salinity Anomaly (Dickson and others, 1988). Delworth and others, (1997) found the 40-80 year periods in the ocean temperature and salinity in the Greenland Sea in a 2000 year integration of a coupled ocean-atmosphere model.

From the time series of total Arctic ice anomaly (Fig. 5), there has been a significant decrease in sea-ice extent since 1970. If the sea-ice thickness of the reduced area is about $1 \mathrm{~m}$ in the last three decades (Rothrock and others, 1999), then the total reduction in ice volume is $964 \mathrm{~km}^{3}$ because SIA has decreased by about $80 \times 110^{2} \mathrm{~km}^{2}$ since the $1970 \mathrm{~s}$. In other words, less ice-equivalent fresh water $(\mathrm{McPhee}$ and others, 1998) must reside in the Arctic surface layer, with a residence time of about 10 years (Aagaard and Carmack, 1989). If the anomalous surface fresh water is transported out of the Arctic through Fram Strait (Kwok and Rothrock, 1999; Vinje, 2001) by the anomalous Transpolar Drift Stream (Steele and Boyd, 1998) into the Western and Eastern Greenland Currents, eventually joining the Labrador Current, this results in stronger than normal stratification of the surface layer in the regions covered by the large anomalous fresh water from the Arctic, i.e. deep-water formation is unlikely to occur. This would result in the shutdown of the deep convection of the dense water and global thermohaline circulation (Mysak and others, 1990; Manabe and Stouffer, 1997). Thus, fresh water is considered an important factor in a feedback loop with decadal cycles (Robitaille and others, 1995; MV98; Ikeda and others, 2001). Furthermore, we need to know what kind of active (rather than passive as a predictor only) role the ASIO plays in global climate change, as well as regional (Arctic) climate change (Wu and others, 1999; Ikeda and others, 2001).

\section{AGKNOWLEDGEMENTS}

We thank the Frontier Research System for Global Change, through JAMSTEC, Japan, for financial support. The authors appreciate fruitful discussions with M. Wallace, J. Walsh, L. Mysak, S. Manabe, K. Yamazaki and S. Minobe.

\section{REFERENGES}

Aagaard, K. and E. C. Carmack. 1989. The role of sea ice and other fresh water in the Arctic circulation. 7. Geophys. Res., 94(C10), 14,485-14,498.

Baldwin, M. P., X. Cheng and T. J. Dunkerton. 1994. Observed correlation between winter-mean tropospheric and stratospheric circulation anomalies. Geophys. Res. Lett., 21 (12), 1141-1144.

Cavalieri, D. J., P. Gloersen, C. L. Parkinson, J. C. Comiso and H. J. Zwally. 1997. Observed hemispheric asymmetry in global sea ice changes. Science, 278(5340), 1104-1106.

Chapman, W. L. and J. E. Walsh. 1993. Recent variations of sea ice and air temperature in high latitudes. Bull. Am. Meteorol. Soc., 74(1), 33-47.

Delworth, T. L., S. Manabe and R. J. Stouffer. 1997. Multidecadal climate variability in the Greenland Sea and surrounding regions: a coupled model simulation. Geophys. Res. Lett., 24(3), 257-260.

Deser, C., J. E. Walsh and M. S. Timlin. 2000. Arctic sea ice variability in the context of recent atmospheric circulation trends. F. Climate, 13(3), 617-633.

Dickson, R. R., J. Meincke, S. A. Malmberg and A. J. Lee. 1988. The "great salinity anomaly" in the northern North Atlantic 1968-1982. Prog. Oceanogr., 20, $103-151$.

Häkkinen, S. 2000. Decadal air-sea interaction in the North Atlantic based on observations and modeling results. F. Climate, 13(6), 1195-1219.

Häkkinen, S. and C. A. Geiger. 2000. Simulated low-frequency modes of circulation in the Arctic Ocean. 7. Geophys. Res., 105(C3), 6549-6564.

Hilmer, M. and P. Lemke. 2000. On the decrease of Arctic sea ice volume. Geophys. Res. Lett., $27(22), 3751-3754$.

Hurrell, J.W. and H. van Loon. 1997. Decadal variations in climate associated with the North Atlantic Oscillation. Climatic Change, 36, 301-326.

Ikeda, M. 1990. Decadal oscillations of the air-ice-ocean system in the 
Northern Hemisphere. Atmosphere-Ocean, 28(1), 106-139.

Ikeda, M., J. Wang and J.-P. Zhao. 2001. Hypersensitive decadal oscillation in the Arctic/subarctic climate. Geophys. Res. Lett., 28(7), 1275-1278.

Jones, P. D. 1994. Hemispheric surface temperature variations: a reanalysis and an update to 1993. 7. Climate, 7(11), 1794-1802.

Kerr, R. A. 1999. A new force in high-latitude climate. Science, 284(5412), 241-242

Kitoh, A., H. Koide, K. Kodera, S. Yukimoto and A. Noda. 1996. Interannual variability in the stratospheric-tropospheric circulation in a coupled ocean-atmosphere GCM. Geophys. Res. Lett., 23(5), 543-546.

Kodera, K., M. Chiba, H. Koide, A. Kitoh and Y. Nikaidou. 1996. Interannual variability of the winter stratosphere and troposphere in the Northern Hemisphere. 7. Meteorol. Soc. Jpn, 74(3), 365-382.

Kwok, R. and D. A. Rothrock. 1999. Variability of Fram Strait ice flux and North Atlantic Oscillation. F. Geophys. Res., 104(C4), 5177-5189. (Erratum: 104(C10), 2000, p. 23,615.

Manabe, S. and R. J. Stouffer. 1997. Coupled ocean-atmosphere model response to freshwater input: comparison to Younger Dryas event. Paleoceanography, 12(2), 321-336.

McPhee, M. G., T. P. Stanton, J. H. Morison and D. G. Martinson. 1998. Freshening of the upper ocean in the Arctic: is perennial sea ice disappearing? Geophys. Res. Lett., 25(9), 1729-1732.

Minobe, S. 1997. A 50-70 year climatic oscillation over the North Pacific and North America. Geophys. Res. Lett., 24(6), 683-686.

Mysak, L. A. and D. K. Manak. 1989. Arctic sea-ice extent and anomalies, 1953-1984. Atmosphere-Ocean, 27 (2), 376-405.

Mysak, L. A. and S. A. Venegas. 1998. Decadal climate oscillations in the Arctic: a new feedback loop for atmosphere-ice-ocean interactions. Geophys. Res. Lett., 25(19), 3607-3610.

Mysak, L. A., D. K. Manak and R.F. Marsden. 1990. Sea ice anomalies observed in the Greenland and Labrador Seas during 1901-1984 and their relation to an interdecadal Arctic climate cycle. Climate Dyn., 5(2), 111-133.

Mysak, L. A., R. G. Ingram, J. Wang and A. van der Baaren. 1996. The anomalous sea-ice extent in Hudson Bay, Baffin Bay and the Labrador Sea during three simultaneous NAO and ENSO episodes. AtmosphereOcean, 34(2), 314-343.

National Snow and Ice Data Center (NSIDC). 1998. Sea ice concentration datasets. NSIDC Notes 24, 1-3.

Parkinson, C. L., D. J. Cavalieri, P. Gloersen, H. J. Zwally and J. C. Comiso. 1999. Arctic sea ice extents, areas, and trends, 1978-1996. 7. Geophys. Res., 104(C9), 20,837-20,856.

Robitaille, D.Y., L. A. Mysak and M. S. Darby. 1995. A box model study of the Greenland Sea, Norwegian Sea, and Arctic Ocean. Climate Dyn., $11(1), 51-70$.

Rogers, J. C. 1990. Patterns of low-frequency monthly sea level pressure vari- ability (1899-1986) and associated wave cyclone frequencies. 7. Climate, 3(12), 1364-1379

Rothrock, D. A., Y. Yu and G. A. Maykut. 1999. Thinning of the Arctic seaice cover. Geophys. Res. Lett., 26(23), 3469-3472.

Slonosky, C. S., L. A. Mysak and J. Derome. 1997. Linking Arctic sea-ice and atmospheric circulation anomalies on interannual and decadal timescales. Atmosphere-Ocean, 35(3), 333-336.

Steele, M. and T. Boyd. 1998. Retreat of the cold halocline layer in the Arctic Ocean. F. Geophys. Res., 103(C5), 10,419-10,435.

Thompson, D.W. J. and J.W. Wallace. 1998. The Arctic Oscillation signature in the wintertime geopotential height and temperature fields. Geophys. Res. Lett., 25(9), 1297-1300.

Thompson, D. W. J., J. M. Wallace and G. C. Hegerl. 2000. Annular modes in the extratropical circulation. Part II: Trend. f. Climate, 13(5), 1018-1036.

Tremblay, L.-B., L. A. Mysak and A. S. Dyke. 1997. Evidence from driftwood records for century-to-millennial scale variations of the high latitude atmospheric circulation during the Holocene. Geophys. Res. Lett., 24(16), 2027-2030.

Van Loon, H. and J. C. Rogers. 1978. The seesaw in winter temperatures between Greenland and northern Europe. Part I: General description. Mon. Weather Rev., 106(3), 296-310.

Vinje, T. 2001. Anomalies and trends of sea ice extent and atmospheric circulation in the Nordic Seas during the period 1864-1998. 7. Climate, 14(2), 255-267.

Vinnikov, K. Ya. and 8 others. 1999. Global warming and Northern Hemisphere sea ice extent. Science, 286(5446), 1934-1937.

Walsh, J. E. and C. M. Johnson. 1979. An analysis of Arctic sea ice fluctuations, 1953-1977. F. Phys. Oceanogr., 9(3), 580-591.

Walsh, J. E., W. L. Chapman and T. L. Shy. 1996. Recent decreases of sea level pressure in the central Arctic. F. Climate, 9(2), 480-486.

Wang, J. and M. Ikeda. 2000. Arctic oscillation and Arctic sea-ice oscillation. Geophys. Res. Lett., 27(9), 1287-1290.

Wang, J., L. A. Mysak and R. G. Ingram. 1994. Interannual variability of seaice cover in Hudson Bay, Baffin Bay and the Labrador Sea. AtmosphereOcean, 32(2), 421-447.

Wang, J., A. van der Baaren and L. A. Mysak. 1995. A principal component analysis of gridded sea-level pressure, surface air temperature, and seaice concentration of the Arctic region, 1953-1993. C ${ }^{2} G C R$ Rep. 95-4.

Wu, B., R. Huang and D. Gao. 1999. Effects of variation of winter sea-ice area in the Kara and Barents Seas on east Asia winter monsoon. Acta Meteorol. Sin., 13(2), 141-153.

Zhang, Y., J. M. Wallace and D. S. Battisti. 1997. ENSO-like interdecadal variability. 7. Climate, 10 (5), 1004-1020. 